Conference abstract PNM01

\title{
Liposomal PEG-Free Creams with Herbal Extracts: Stability Study
}

\author{
I. ARsić ${ }^{1}$, V. TAdić ${ }^{1}$, D. Runjaić-Antić ${ }^{1}$, S. ĐorøeVIĆ ${ }^{1}$, I. HOMŠEK $^{2}$ \\ ${ }_{1}^{1}$ Institute for Medicinal Plants Research "Dr Josif Pančić", Tadeuša Košćuška 1, Belgrade, Serbia \\ ${ }^{2}$ Galenika Institute, A.D., Batajnički drum B.B., 11000 Belgrade, Serbia \\ E-mail: iarsic@mocbilja.rs (I. Arsic)
}

Sci Pharm. 2010; 78: 671

doi:10.3797/scipharm.cespt.8.PNM01

The propylene glycol Liquorice, Marigold and Yarrow extracts (LE, ME, YErespectively) were obtained by the repercolation method, in the plant:extract ratio 1:2. Its appearance, relative density, index of refraction, $\mathrm{pH}$ values and dry materials content were evaluated. The extracts were encapsulated into the instant liposome (Natipide ${ }^{\circledR}$ II, Nattermann Phospholipids, Germany). Liposomal encapsulation of LE, ME and YE extracts was done by mixing of instant liposomes and the extract (2:1) in an ultrasound bath for 10 min. The obtained dispersions were diluted with purified water, in the ratio 1:1 and homogenised during 15 min to get final dispersion LD, MD and YD, respectively. Average radius of the liposoms size in dispersions was determined spectrofotometrically. For obtaining the $\mathrm{O} / \mathrm{W}$ emulsion-type creams-vehicle, applying the cold-cold method, we used 5\%w/w Emulgin ${ }^{\circledR}$ VL75 emulsifier [Lauryl Glycoside (and) Polyglyceryl-2 Dipolyhydroxystearate (and) Glycerine] (Cognis, Germany). The composition of vehicle is the same as described previously [1]. The extracts LE, ME and YE (5\% w/w) were incorporated in the vehicle (LC, MC and YC creams obtained). The liposomal dispersions LD, MD and YD were incorporated (30\%) in the vehicle to obtain LLC, MLC and YLC creams, respectively. Liposomal creams (LLC, MLC, YLC) and nonliposomal creams (LC, MC, YC) were inspected simultanously: stability under storage: at room temperature $\left(22^{\circ} \mathrm{C} \pm 2\right)$, in hot air at $45^{\circ} \mathrm{C} \pm 2$ and at $5^{\circ} \mathrm{C} \pm 2$; centrifuge test: centrifuged in two 15 -minutes runs, each at $3000 \mathrm{rpm}$; organoleptic properties inspected both visually and by smear tests on glass slabs: appearance, colour, odour and homogeneity of the samples; $\mathrm{pH}$ values of the creams were obtained by direct potentiometric method; rheological characterization of creams: Rotovisko RV 12 with coaxial sensor cylinder systems SVst, Svdin, was used (measurements carried out at $20 \pm 0,1^{\circ} \mathrm{C}$ with shearing rates continuously changing within the ratio from 0 to $\left.110 \mathrm{~s}^{-1}\right)$. The results indicate that emulsifier mentioned in the text above is suitable excipient for preparation of stable o/w creams-vehicles for incorporation of LE, ME and YE as well as liposomes filled with extracts.

This work was supported by Serbian Ministry of Science and Technological Development, project number TR 20137.

[1] Cupara S, Arsic I, Homsek I, Tadic V, Jankovic S, Djordjevic S. Moisturizing effect of o/w oleosom structure creams containing sea buckthorn fatty oil and olive oil. Book of Abstract, No $35,6^{\text {th }}$ World Meet Pharm. Biopharm. and Pharm. Technol, 7-10 04. 2008, Barselona, Spain. 